\title{
Águas da desunião nacional: representações da transposição do rio São Francisco
}

\author{
Waters of national disunity: representations of transposition São Francisco River
}

\author{
Lauriston de Araújo Carvalho ${ }^{1}$ \\ Maria Cristina Smith Menandro 2
}

\begin{abstract}
RESUMO: Nessa última década, as secas tornaram-se mais frequentes nas regiões brasileiras, por isso a água tem se tornado um bem constantemente debatido nos meios de comunicação. Entendendo a integração de rios com bacias hidrográficas como política pública fundamental de acesso à água, o presente estudo objetivou conhecer as representações sociais da transposição do rio São Francisco no Jornal Estado de Minas entre 1999 e 2008. A coleta foi realizada no site do jornal, perfazendo um total de 316 reportagens. Para tratamento dos dados foi utilizado o software Alceste. Os resultados mostram discursos contra e a favor do projeto nos governos FHC e Lula. Os discursos contrários ao projeto clamam pela revitalização do rio. Através das falas dos pescadores, o rio é objetivado na figura de uma pessoa doente em virtude do seu estado degradado e ancorado em épocas de matas ciliares preservadas. A revitalização seria a salvação do rio, tornando-se principal argumento contra o projeto. Paralelamente, o uso da transposição para fins econômicos torna-o questionável e ancorado ao histórico de obras públicas inconclusas no Nordeste e de objetivos escusos. Nos discursos favoráveis, propalados especialmente por políticos, a transposição é imprescindível para o desenvolvimento econômico do Nordeste. Tais desenvolvimentos são elementos representacionais ligados à ideia de seca, pois as estiagens contribuíram para as históricas migrações forçadas e estagnação do desenvolvimento da região. Dessa forma, na problemática da crise hídrica, a ideia da transposição como propulsor do desenvolvimento e remediação da seca, mostra-o como redentor do Nordeste/nordestino, explorado pelo jornal e propagandas governamentais.
\end{abstract}

Palavras-chave: representação social; rio São Francisco; transposição; meio ambiente; imprensa.

\begin{abstract}
In this last decade droughts have become more frequent in the Brazilian regions, where the water becomes constantly discussed in the media. Understanding the transposition of the São Francisco River as a fundamental public policy on these problems, this study aimed to understand the social representations of the transposition of the São Francisco River in the Estado de Minas newspaper from 1999 to 2008. The collection was made in the newspaper's website, making a total of 316 reports. The data collected was analyzed by Alceste software. The results show speeches against and favor of the project in the FHC and Lula administrations. Speeches against the project claim for the revitalization of the river. Through the speeches of fishermen, the river is objectified a sick person because of its degraded state and anchored in preserved riparian forests. The revitalization would be the salvation of the river, becoming main argument against the project. Same time, the use of transposition for economic purposes becomes questionable and anchored to the history of unfinished public constructions in the Northeast and shady goals. Speeches in favor, made especially by politicians, transposition is essential for the economic of the Northeast. Such development is representational element linked to the idea of drought, therefore, the aridity contributed to the historical migration and stagnation of the region. Thus, in the water crisis, the idea of transposition as a driver of
\end{abstract}

\footnotetext{
${ }^{1}$ Mestre em Psicologia pela Universidade Federal do Espírito Santo (UFES). Doutorando pelo Programa de Pós-Graduação em Psicologia (PPGPSI) da Universidade Federal do Rio Grande do Norte (UFRN) - Natal, RN, Brasil. E-mail: lauristonac@hotmail.com.

2 Doutora em Psicologia pela Universidade Federal do Espírito Santo (UFES). Professora Associada do Departamento de Psicologia Social e do Desenvolvimento, na Universidade Federal do Espírito Santo, atuando na Graduação e no Programa de Pós-Graduação em Psicologia - Vitória, ES, Brasil.
} 
development and remediation of drought, shows him as redeemer of the Northeast/northeastern, exploited by newspaper and government advertisements.

Keywords: social representation; São Francisco river; transposition; environment; press.

\section{Introdução}

Do que se tem conhecimento, o fenômeno cíclico das estiagens tem registros históricos seculares e consequências arrasadoras em território brasileiro (Villa, como citado em Departamento Nacional de Obras Contra as Secas [DNOCS], 2009). Nessa última década, as secas gradativamente tornaram-se mais frequentes em diversas regiões brasileiras, causando graves impactos na oferta de água para o abastecimento público, irrigação e geração de energia elétrica; alertando para a necessidade de debate e a procura por soluções a nível nacional (Agência Nacional de Águas [ANA], 2014).

Em busca de saídas para a problemática, o projeto da transposição das águas do rio São Francisco surge como solução para o problema da escassez de água (Castro, 2011). O projeto de Integração do rio São Francisco com as Bacias Hidrográficas do Nordeste Setentrional (nome oficial) é de responsabilidade do governo federal em conjunto com o Ministério da Integração. O seu principal objetivo é assegurar a oferta de água a cerca de 12 milhões de pessoas em 390 municípios da região semiárida dos estados de Pernambuco, Ceará, Paraíba e Rio Grande do Norte até o ano 2025 (Agência Senado, 2012). Para atingir esse intento, o governo prevê a construção de dois canais, Eixo Norte e Eixo Leste, que levariam $26,4 \mathrm{~m}^{3} / \mathrm{s}$ de água do Rio São Francisco às bacias e açudes espalhados pelo Nordeste Setentrional.

Numa perspectiva histórica, a transposição do rio São Francisco aparece na época do Brasil colônia nas épocas de estiagens como solução para a problemática da falta de água e quase sempre provoca debates quando cogitada (Ribeiro, 2010; Castro, 2011). Contudo, foram nas décadas de 1990 e 2000 que o projeto figurou como tema controverso e dividiu opiniões no cenário político brasileiro e na sociedade civil. Considerando que os veículos midiáticos impressos foram fundamentais na disseminação de informações sobre o projeto, voltar nossa atenção para análises documentais da imprensa escrita nessas últimas décadas parece ser uma maneira interessante de reconstituição e compreensão de determinada realidade histórica (Souza \& Menandro, 2007).

No que se refere aos estudos que buscam compreender a relação da mídia com o grande público, recorremos à Teoria das Representações Sociais (TRS) para a compreensão do fenômeno da transposição do rio São Francisco na mídia impressa nacional (Moscovici, 2003). A TRS se propõe ao entendimento da realidade cotidiana a determinados grupos sociais cujo conhecimento do senso comum ganha relevo e é pensado como saber determinante de atitudes, comportamentos e práticas sociais (Jodelet, 2001).

Como processos formadores das representações sociais, a ancoragem e a objetivação são faces indissociáveis. Na ancoragem, o que se pretende é o ajustamento de um objeto social inédito e perturbador a um pensamento social familiar pré-existente. Suas funções dizem respeito a incorporação do que é estranho ou novo, a interpretação da realidade e a orientação das práticas sociais (Espíndula, 2010). A objetivação se refere à simplificação de ideias que se associam a imagens do mundo físico, o que implica a seletividade de elementos 
e sua descontextualizarão, "dependendo de significados pré-existentes frutos da inserção grupal" (Vasconcellos, 2013, p. 41).

Visando compreender as formas de organização dos conteúdos emitidos pela mídia de massa sobre determinado objeto social, Moscovici (2012) delimita os Sistemas de Comunicação Difusão, Propagação e Propaganda. A Difusão, exemplificada no estudo original de "a grande imprensa", é direcionada a um público diversificado e o conteúdo objetiva se adequar às preferências do seu leitor. As notícias são quase sempre de cunho sensacionalista e se propõe apenas informar, sem posicionamento determinante frente ao fenômeno social apresentado. A Propagação é direcionada a grupos sociais específicos com ideologias já cristalizadas. O objetivo das mensagens é adequar certos objetos estranhos, comportamentos e normas que podem desestabilizar o pensamento social existente. Já a Propaganda é a forma de comunicação em que as mensagens são bem definidas e estruturadas, admitindo posicionamentos frente ao objeto em questão. O que está claro nas mensagens disseminadas é o componente persuasivo se relacionando diretamente com os estereótipos. Esses processos comunicacionais são responsáveis pelas formas de organização dos conteúdos emitidos, que sobressai dentro de um contexto no qual são levadas em consideração as características de uma sociedade, grupo ou instituição social em questão e também a qualidade das interações sociais.

Há uma diversidade de estudos documentais que tem buscado compreender as ideias contidas em revistas e jornais sobre fenômenos sociais a partir da TRS. O estudo documental feito por Carvalho e Espíndula (2014) buscou entender como diferentes jornais no estado de Pernambuco (Gazzeta do São Francisco e Jornal do Commercio) compreendiam e construíam no imaginário social o projeto da transposição do rio São Francisco nos anos 2004 e 2005. A partir dos resultados, os autores chegaram à conclusão que a localização do jornal dentro do estado de Pernambuco determinava os conteúdos e as formas das reportagens sobre o projeto da transposição. Coutinho, Araújo, Coutinho, Morais e Batista (2014) objetivaram conhecer o que a mídia impressa veiculava acerca das eleições presidenciais no Brasil (2014) a partir de materiais textuais coletados. Já Oliveira, Nascimento-Gianordoli, Santos e Freitas (2015) buscaram compreender o processo de construção de representações sociais do tráfico de drogas ao longo da história recente do país, a partir de matérias da revista Veja, do período entre 1968 e 2010.

A partir desse panorama, os veículos de comunicação impressos acompanharam todo o processo de elaboração do projeto da transposição até o início das obras, como também as polêmicas geradas em seu entorno com inúmeras reportagens e notícias. Sendo assim, os jornais foram fontes essenciais de informação a diversos atores sociais sobre o projeto de transposição do rio São Francisco e importantes instrumentos para a produção de representações sociais. Por se tratar de um projeto secular, a transposição atravessou diferentes cenários políticos, sendo entendido de formas distintas pelos meios de comunicação, principalmente, no que se refere às décadas de 1990 e do ano 2000. O estado de Minas Gerais, onde está localizado a nascente do rio São Francisco, insere-se nesse cenário como doador das águas da transposição e, dessa forma, fundamental na compreensão de toda a problemática que envolve o projeto. Logo, o presente estudo objetivou conhecer as representações sociais da transposição do rio São Francisco no Jornal do Estado de Minas entre os anos 1999 e 2008. 


\section{Método}

O presente estudo se refere a uma pesquisa documental descritiva, com material jornalístico noticioso no Jornal Estado de Minas. Esse periódico foi escolhido por ser o de maior distribuição em Minas Gerais, que é o estado doador das águas da transposição. Ao ser observado que as primeiras reportagens sobre o projeto aparecem no ano de 1999 e que o início das obras se dá no ano de 2007, buscamos, então, analisar todas as reportagens sobre a transposição do rio São Francisco dos anos 1999 até 2008 - período estabelecido até $o$ ano seguinte ao início das obras.

O jornal Estado de Minas faz parte de um conglomerado de empresas de mídia chamado Diários Associados, também conhecido como Condomínio Acionário dos Diários e Emissoras Associados. Hoje, é o sexto maior conglomerado de empresas de comunicação do país, atuando em várias áreas, como televisão, internet, jornais, revistas, rádios e empresas de cinevídeo. A tiragem é diária, com aproximadamente 71.926 exemplares nos dias úteis e 102.034 aos domingos. O público consumidor é composto das mais variadas classes sociais, porém, entre os jornais que circulam na grande Belo Horizonte é o que apresenta maior número de leitores com cargos em nível superior, graduados, pós-graduados e possuem renda familiar a partir de dez salários mínimos (Diários Associados, 2016).

O procedimento de busca pelas reportagens se deu via internet. A coleta aconteceu no próprio site do jornal, www.impresso.em.com.br, a partir dos descritores: transposição; rio São Francisco; transposição águas São Francisco. Foram encontradas 316 reportagens, que foram salvas num banco de dados e classificadas segundo os critérios de número de entrada e ano.

A análise dos dados se deu com a leitura exaustiva das reportagens e posterior ajuda do software Alceste (Analise Contextual de um conjunto de Segmentos de Texto) (Camargo, 2005). O programa realiza análises estatísticas de dados textuais de um corpus previamente preparado que constitui-se do material textual sobre um tema (transposição do rio São Francisco), formado com o agrupamento de todas as UCls (reportagens sobre o tema que, nesse caso, totalizaram 316), processados por meio de variáveis previamente estabelecidas, são elas: número de entrada da reportagem no banco de dados (Mat_número); ano de publicação da reportagem (Data_ano) e variável política (VP_FHC/LULA). O corpus é, então, dividido em segmentos de texto constituído de enunciados linguísticos (Unidades de Contexto Elementar - UCE) que serão a base para análises mais refinadas. Como, por exemplo, a Classificação Hierárquica Descendente sob a forma de Dendrograma, que permite visualizar graficamente as classes de ideias e sua correlação de proximidade; e a Classificação Hierárquica Ascendente, que é uma análise fundamentada no léxico das palavras com cruzamentos das classes e UCEs (exibidas aqui em itálico e chanfrado as palavras mais representativas). Por fim, com o propósito de complementar uma informação dada pelo programa ou contextualizar um fato histórico, fazemos uso também de trechos das reportagens transcritos na íntegra. 


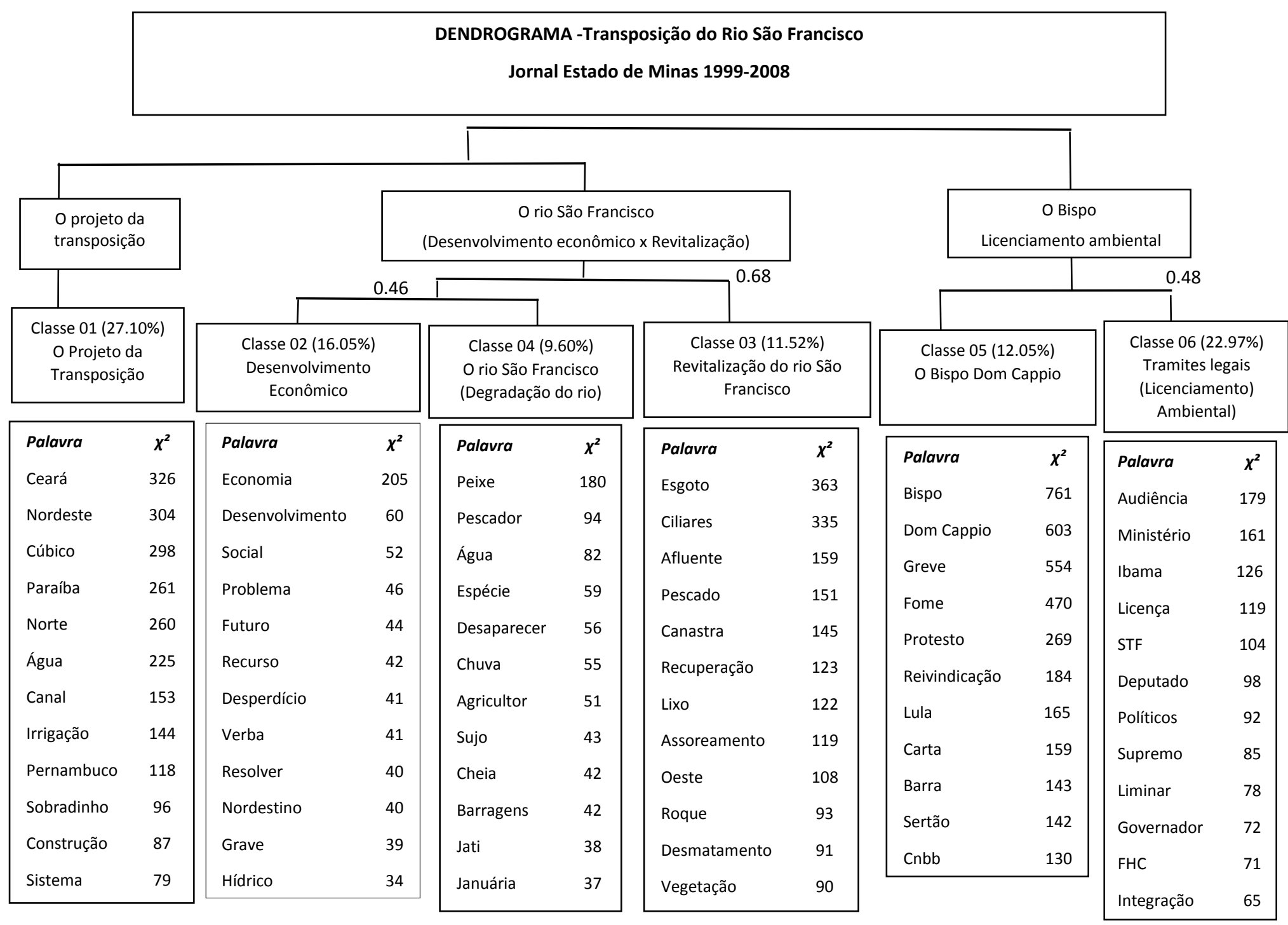

Figura 1 - Dendrograma - Transposição do Rio São Francisco, Jornal Estado de Minas 1999-2008

A análise hierárquica descendente preservou $80.16 \%$ de todo o material processado. Como mostra a figura 01, a análise apontada pelo programa apresenta seis classes organizadas em torno de três grandes eixos: 1.0 projeto da transposição; 2.0 rio São Francisco (Desenvolvimento econômico x Revitalização) e 3.0 Bispo e o Licenciamento ambiental. A fim de facilitar o entendimento das classes, serão apresentados trechos das respostas que mais expressam as ideias contidas nas classes.

O primeiro eixo apresenta a classe 01 - O projeto da transposição. O segundo eixo é composto pelas classes 02 - Desenvolvimento econômico (aspectos positivos) e 04 - 0 rio São Francisco (Degradação do rio), que se ligam numa correlação de 0.46 e que, por sua vez, ligam-se à classe 03 -Revitalização do rio São Francisco numa correlação de 0.68. Por fim, o terceiro subeixo agrupam as classes 05 - O Bispo Dom Cappio e 06 - Tramites legais (Licenciamento ambiental) numa correlação de 0.48.

O eixo "O projeto da transposição" apresenta a classe 01 em sua composição. Esta, por sua vez, descreve o projeto da transposição do rio São Francisco a partir dos canais leste e norte que percorrem os estados de Pernambuco, Paraíba, Ceará e Rio Grande do Norte; 
citando os pontos de captação localizados em Cabrobó-PE e no lago de Itaparica, no mesmo Estado: "O \#preço da megalomania. A \#transposição vai \#custar \#quase uma \#usina \#hidrelétrica do \#porte de Três \#Marias \#somadas a \#energia que \#será gasta no \#bombeamento da \#água \#para a \#Paraíba, \#Rio \#Grande do \#Norte e \#Ceará" (Classe 01); "O \#vale do \#Assu é também chamado de \#polígono do \#camarão, é uma cultura que consome \#duas vezes mais \#água do que a \#agricultura \#irrigada" (Classe 01).

Como é possível perceber na análise ascendente realizada pelo Alcest, o jornal entende o projeto como megalomaníaco por exigir investimentos próximos do que custaria uma hidrelétrica do porte da Três Marias. A usina de Três Marias está localizada na região central do estado de Minas Gerais e tem capacidade para abastecer 1,1 milhões de pessoas ao custo de aproximadamente $\mathrm{R} \$ 2$ bilhões (Cemig, 2012).

O uso das águas da transposição para fins econômicos (criatória de camarão e irrigação) aparece no governo Lula, no ano de 2004, fazendo com que o projeto seja, então, questionado em seu principal objetivo de levar água para abastecimento humano no semiárido nordestino. A oposição ao projeto não ocorre nos anos anteriores, pois as críticas dizem respeito à revitalização do rio, e não a uma oposição ao projeto da transposição.

No ano 2001, por exemplo, o governo federal deu andamento legal ao projeto sem levar em consideração a revitalização do rio antes de transpor as águas, tal qual foi idealizado pelo governo do estado de Minas Gerias. A insatisfação, principalmente, com o tratamento dado pelo governo federal no Relatório de Impacto Ambiental (Rima) sobre a revitalização foi crucial para tornar o projeto alvo de críticas e serviu como argumento contra o projeto durante todo esse ano. Porém, no ano de 2004, ao se ponderar o destino das águas para fins econômicos, o jornal Estado de Minas lançou uma série de dezesseis reportagens denominada "A verdade sobre a transposição do rio São Francisco" questionando o real objetivo e demarcando definitivamente uma posição avessa ao projeto.

Paralelamente à ideia das intenções subjacentes ao real objetivo da transposição, o projeto é comparado pelo jornal ao histórico de obras públicas de abastecimento hídrico e irrigação que estão inconclusas. A série de reportagens traz o exemplo dos projetos de irrigação São Gonçalo e Várzeas de Souza na cidade de Souza-PB: "A história dos projetos de irrigação São Gonçalo e Várzeas de Sousa revela como, em nome da população assolada pela seca, centenas de milhões de reais são investidos em obras conflitantes e ineficazes, muitas vezes contaminadas por disputas políticas locais" (Estado de Minas, 12/06/2004). Segundo o jornal, o projeto São Gonçalo foi planejado para ter três mil hectares de lavouras, mas irriga apenas 1,5 mil hectares nos anos em que há reserva de água nos açudes associados. No caso do projeto Várzeas de Sousa, inaugurado em 2002, ao custo de R\$ 105 milhões, nenhum hectare é irrigado.

O subeixo $O$ rio São Francisco (Desenvolvimento econômico x Revitalização) é composto pelas classes 02 - Desenvolvimento econômico - Aspectos positivos e 040 rio São Francisco (Degradação do rio São Francisco), que por sua vez se ligam à classe 03 Revitalização do rio São Francisco. A classe 02 apresenta a transposição como uma medida necessária para o desenvolvimento da região Nordeste, que se justificaria por ser o resgate de uma dívida social do país à região. Assim, a transposição "\#representa uma parcela \#importante de \#um conjunto de \#medidas \#necessárias ao \#desenvolvimento da \#região e ao resgate da chamada dívida \#social do \#pais com aquelas \#comunidades" (Classe 02) 
As classes 02 e 04 ligadas numa correlação de 0.46 abordam o desenvolvimento econômico e a degradação do rio São Francisco. Nos relatos de pescadores, barranqueiros e ribeirinhos, a degradação é percebida como consequência da construção de hidroelétricas, uso abusivo de agrotóxicos por plantadores de cana e poluição urbana, afetando diretamente na reprodução e o desaparecimento de determinadas espécies de peixes: "\#com a construção das hidrelétricas, não \#tem \#mais água em \#quantidade suficiente para garantir a reprodução \#dos \#peixes. Os \#plantadores de cana usam agrotóxicos e \#fazem pulverização \#com máquinas aéreas, \#denuncia o ambientalista" (Classe 04)

Tanto no governo FHC quanto no Lula, o estado de degradação em que se encontra o rio São Francisco é sempre lembrado e comparado à épocas passadas. Ainda nos relatos de grupos dos ribeirinhos, é possível constatar uma imagem discrepante do rio no passado e apresentado no presente, no que se refere aos aspectos e nível da água, estrutura física do rio e alternativas de pesca de determinadas espécies de peixe: "\#Antes o \#rio era todo limpo, \#agora, \#está \#mais estreito, \#com essas garrafas plásticas chegando até \#aqui, protesta" (Classe 04); "Ele conta que \#antes \#pescava \#muito Matrinchã. \#Hoje não encontra \#mais essa \#espécie de \#peixe" (Classe 04); "\#Antes o rio São Francisco enchia, \#hoje não enche \#mais, \#com \#isso o \#peixe não \#tem \#mais condições de fazer a desova" (Classe 04).

A classe 03 liga-se às classes anteriores (classes 02 e 04) por apresentar a medida necessária para contornar a degradação do rio São Francisco e a possibilidade, então, de realização da transposição. A revitalização do curso de água é entendida como medida eficaz para o combate à sua degradação e sua preservação através do tratamento dos esgotos domésticos, recuperação das matas ciliares, eliminação do garimpo, controle da mineração, monitoramento da cunha salina, etc.,: "\#medidas de \#revitalização do rio defendidas pelo ambientalistas, estão o \#tratamento dos \#esgotos \#domésticos, \#recuperação \#das \#matas \#ciliares, eliminação do \#garimpo, \#controle da mineração, \#monitoramento da \#cunha \#salina" (Classe 03).

As críticas ao projeto da transposição em Minas Gerais ocorrem em torno da questão da revitalização do rio São Francisco, como dito anteriormente. Os principais críticos no governo FHC, além do governo do estado, foram as Organizações Não-Governamentais (ONG) e os ambientalistas insatisfeitos com o tratamento dado no Relatório de Impacto Ambiental (Rima) sobre a revitalização do rio.

No governo Lula, de forma semelhante ao governo antecessor, as preocupações do estado de Minas Gerais e dos ambientalistas dizem respeito ao estado degradado do rio, e as discussões sobre o projeto dizem respeito à sua revitalização antes do início das obras no qual a sobrevivência do rio é amplificada nos debates. O presidente do Comitê da Bacia do rio Paraopeba, Mauro da Costa Val, por exemplo, chama a atenção para a sobrevivência do rio, caso a sua recuperação não seja realizada: "Se não quiserem que o rio São Francisco sobreviva, tem que tratar o esgoto, tem que preservar suas matas" (Estado de Minas, 08/09/2003).

O terceiro Subeixo denominado O Bispo e o Licenciamento Ambiental tem na sua composição as classes 05 - O Bispo Dom Cappio e 06 - Tramites Legais (Licenciamento Ambiental, numa correlação de 0.48. A classe 05, que trata do Bispo Dom Cappio, descreve o cotidiano da greve de fome: "Canja \#na primeira refeição após \#jejum. \#Depois de 11 \#dias de \#greve \#fome, o \#Dom Cappio \#fez a primeira refeição \#uma canja \#ao meio dia de \#ontem, na casa vizinha a \#capela São \#Sebastiao, \#onde se instalou" (Classe 05). 
Nesses 10 anos de elaboração do projeto de transposição, o Bispo Dom Cappio realizou duas greves de fome em protesto. A primeira aconteceu em outubro de 2005, permanecendo por 11 dias em jejum até que Lula arquivasse o projeto. A segunda aconteceu em novembro de 2007. Ele permaneceu 24 dias sem ingerir alimentos em razão do processo licitatório determinando o início das obras. A repercussão da greve de fome causou a comoção da opinião pública, estimulando manifestações de apoio nos estados de Minas Gerais, Brasília, Bahia e Pernambuco.

Esse movimento por reivindicações do Bispo Dom Cappio, no ano 2005 e 2007, aconteceram em épocas específicas em que foi possível vislumbrar o início das obras da transposição por meio dos processos licitatórios realizados pelo Ibama, CBHSF e CNRH, autorizando as licenças ambientais para execução do projeto. A classe 06 - Tramites Legais (Licenciamento Ambiental) relaciona-se a classe 05 numa correlação de 0.48 por apresentar os tramites legais desses processos licitatórios, como pode ser visto na análise ascendente a seguir: "\#presidente \#do \#lbama, Marcus Barros, assinou a \#licença de \#instalação da \#Transposição do \#rio \#São \#Francisco e, anteriormente, o \#Ministério da \#Integração \#Nacional publicou o aviso de \#licitação \#pública da \#primeira \#etapa da \#obra" (Classe 06)

A pressão de governos estaduais e ambientalistas contra a transposição foi responsável pelo cancelamento de várias audiências públicas, sendo um dos principais motivos para a não execução do projeto no governo FHC. O jornal Estado de Minas nomeia três fatos fundamentais que impediram a concretização do projeto nesse governo, são eles: 1. Cancelamento das Audiências Públicas, 2. Saída do senador Fernando Bezerra (PMDB-RN) no cargo de Ministro da Integração Nacional, 3. Racionamento de água em várias regiões do país.

Nos anos entre 1999 e 2002, alguns municípios mineiros e estados nordestinos vivenciavam um período de estiagem e o desvio das águas do São Francisco comprometeria a geração de energia nas usinas de Xingó, Sobradinho e Paulo Afonso. Dessa forma, o projeto é arquivado e volta à mesa de negociações no governo subsequente sendo executado apenas no ano de 2007.

\section{Discussão dos resultados}

A partir dos resultados descritos é possível perceber que as posições contra e a favor da transposição do rio São Francisco estiveram presentes no governo FHC (1999-2002) e durante todo o governo Lula (2003-2008). Essas posições surgem nos estados da federação doadores e receptores das águas e ganham voz nos diferentes personagens políticos e da sociedade civil ao passar dos anos, contribuindo por existir representações interdependentes e correlatas favoráveis ou não à transposição.

Dito isto, em relação ao grupo dos estados doadores e, portanto, contra o projeto, os elementos representacionais começam a aparecer no governo FHC a partir do ano 2000 e agrupados no subeixo $O$ rio São Francisco (Desenvolvimento econômico x Revitalização) a começar com a classe 04 - O rio São Francisco (Degradação do rio). A degradação do rio percebida como resultado da construção de hidrelétricas, uso abusivo de agrotóxicos e a poluição urbana - faz com que os movimentos sociais e ambientalistas constatem a sua fragilidade, objetivando o estado em que se encontra o rio numa pessoa doente, necessitando de cuidados, como no exemplo a seguir extraído de uma reportagem: "são 
como extrair sangue de doente combalido. Todos sabem que a bacia do rio São Francisco está degradada", anêmico não doa sangue" (Estado de Minas, 16/05/2003).

Essa forma de objetivação do rio São Francisco numa pessoa debilitada também aparece no estudo de Carvalho e Espíndula (2014) sobre a transposição do rio São Francisco nos jornais pernambucanos. Segundo o estudo, a imprensa representa o rio "a partir de uma imagem degradada, objetivada como um rio com pouca água, desmatado, poluído e assoreado. Essa imagem é reproduzida em um discurso recorrente em várias reportagens" (p. 140). Com base nesses elementos os autores completam: "'Velho Chico" é objetivado na imagem de uma pessoa doente e na fase terminal, precisando urgentemente de cuidados" (p. 148)

A consequência da degradação e o temor do esvaziamento da bacia fazem com que os movimentos sociais e ambientalistas clamem pela a sobrevivência e salvação do rio. Tanto no governo FHC, quanto no governo Lula, o estado de é ancorado na memória do estado físico do rio São Francisco em épocas passadas, a partir de relatos de pescadores, barranqueiros e ribeirinhos, presentes, principalmente, na classe $04-O$ rio São Francisco (Degradação do rio).

Noutro relato extraído de uma reportagem, um pescador fala do São Francisco de três décadas atrás, com as suas matas ciliares preservadas e diversas espécies de animais: "há cerca de 30 anos atrás, a beira do rio São Francisco era cheio de mato, com muitos bichos, incluindo onças e capivaras. Também havia jacarés, principalmente, nas lagoas marginais" (Estado de Minas, 25/06/2003). No relato é possível constatar um rio vigorante, "cheio de mato" (referência a preservação das matas ciliares), "com muitos bichos", como onças, capivaras, jacarés, discrepante ao que é rio São Francisco se mostra no presente.

Como já dito nos resultados, as preocupações do estado de Minas Gerais e dos ambientalistas dizem respeito à revitalização antes do início das obras em que a sobrevivência do rio é amplificada nos debates. A discussão da revitalização, presente na classe 03, é a medida eficaz para sanar a problemática da degradação do rio através do tratamento dos esgotos domésticos, recuperação das matas ciliares, eliminação do garimpo, controle da mineração e monitoramento da cunha salina. Assim, a revitalização seria o "remédio" necessário para o tratamento de uma "enfermidade" que seria a degradação, o "antídoto" para um rio que está "doente".

Em 2004, governo Lula, o uso das águas da transposição para fins econômicos, criatório de camarão e irrigação fazem com que o projeto seja, então, questionado em seu principal objetivo de levar água para abastecimento humano no semiárido nordestino, encadeando a afirmação de todo um posicionamento contrário. Esse episódio, especificamente, faz gerar debates sobre o projeto da transposição e agregar outros elementos de representação, até então inexistentes nos anos anteriores do governo Lula e no governo FHC.

A partir desse episódio, a transposição é, então, ancorada ao secular histórico de obras públicas de abastecimento hídrico e irrigação inconclusas no semiárido nordestino. A série de portagens "Verdades sobre o rio São Francisco" traz os exemplos dos projetos de irrigação São Gonçalo e Várzeas de Souza, ambos na cidade de Souza-PB, que foram investidos centenas de milhões de reais e nunca foram concluídos. A transamazônica, obra pública de grande dimensão que abriu rodovias que interligavam os estados da Paraíba, Piauí, Maranhão, Pará e Amazonas, considerada pelo jornal como uma obra "faraônica", 
também é lembrada e comparada ao projeto da transposição - projeto megalomaníaco como mais uma obra de alto custo e considerada também a redenção da região Amazônica, mas nunca foi concluída.

No que se refere aos estados receptores das águas, e, portanto, a favor do projeto, os elementos representacionais aparecem na classe 02 - Desenvolvimento Econômico (Aspectos positivos). A classe em questão apresenta a transposição das águas como uma medida necessária para o desenvolvimento da região Nordeste que se justifica por ser o resgate de uma dívida social do país à região.

O Nordeste, e, principalmente, o semiárido nordestino, alimenta o imaginário social brasileiro como uma região de muita miséria em decorrência da seca (Leitão \& Santos, 2012). Dessa forma, os discursos da geração de emprego e renda são elementos representacionais que se ligam a ideia de seca porque as consequências desse fenômeno contribuem para a estagnação do desenvolvimento econômico do lugar. A estagnação econômica e a miséria do Nordeste aparecem como consequência dos poucos investimentos dos governos ao longo de décadas na região, por isso a transposição é vista como forma de compensação e pagamento de uma dívida histórica, sendo elemento representacional que se liga aos anteriores.

A possibilidade de desenvolvimento econômico e remediação dos efeitos da seca mostram o projeto como redentor do Nordeste/nordestino: "Perdeu a nação brasileira uma excelente oportunidade de ver construída esta monumental obra de engenharia que faria a redenção do Nordeste brasileiro" (Estado de Minas, 11/06/2001); "uma obra para fins múltiplos e que poderia ter sido a redenção do Nordeste" (Estado de Minas, 03/05/2000).

A estreita relação entre o projeto e a solução para a seca no Nordeste é apontada por Meiron (2009), Ribeiro (2010) e Castro (2011) quando observam que o projeto sempre foi cogitado nas épocas de calamidades de falta d'água, aparecendo como única medida eficaz e definitiva para a problemática. Num largo tempo histórico, a seca foi combatida através de grandes propostas de engenharia que prometiam a remediação dos seus efeitos. A transposição é, então, apresentada como mais um desses esboços que anunciavam a eliminação da escassez de água e por isso disseminada pelo jornal como a solução dos efeitos da estiagem, configurando-se assim na redenção do povo nordestino de livrar-se da secular problemática da seca.

Em relação ao jornal Estado de Minas, algumas características indicam que o periódico utiliza da Propagação e também de Propaganda (Moscovici, 2012). A Propagação, como Sistema de Comunicação direcionada a grupos sociais específicos (Allain, NascimentoSchulze \& Camargo, 2009), parece dirigir suas reportagens ao público mineiro em geral e também ao ribeirinho, pescador e barranqueiro por causa grande quantidade de reportagens sobre o cotidiano do rio São Francisco. Haja vista que o São Francisco nasce no estado mineiro, podemos dizer que a proximidade com o rio contribuiu para uma maior quantidade de reportagens que tratavam da sua revitalização, mostrando maneiras que o degradavam, localidades em que o rio estava mais vulnerável e discutindo soluções para a sua recuperação.

O direcionamento das reportagens a ribeirinhos e pescadores em virtude da proximidade com o rio aparece novamente no estudo de Carvalho e Espíndula (2014). 0 jornal Gazzeta, por estar localizado no município de Petrolina-PE semiárido nordestino e banhado pelas águas do São Francisco, dirige suas notícias a um público que vive próximo ao 
rio e depende diretamente de suas águas cujas questões do cotidiano do rio aparecem nas notícias, diferente do Jornal do Commercio, inserido no centro político-econômico do Estado de Pernambuco.

A maneira como o noticiário trata o projeto da transposição no governo FHC (19992002) e início do governo Lula (2003-2004) parecer ser imparcial. As notícias transmitem os argumentos de ambas posições e parecem acompanhar a discussão como expectador, principalmente, sobre as disputas políticas entre os estados/políticos nordestinos. Como já mencionado, as críticas quando aparecem dizem respeito à exigência da revitalização do rio São Francisco antes do início das obras, mas não uma oposição ao projeto. Essa postura frente ao planejamento nesses anos do governo FHC e início de Lula pode ter contribuído para uma postura mais "neutra" com intenções de transmitir informações sobre o cotidiano do rio e demonstrar preocupações com a sua revitalização.

No entanto, no ano 2004, a possibilidade de uso das águas da transposição para fins econômicos, irrigação e criatório de camarão faz com que o jornal mude a sua postura em relação ao projeto e apresente traços do Sistema de Comunicação a Propaganda. Nesse momento, o foco do periódico é o projeto da transposição no qual há o levantamento de questionamentos em relação aos objetivos de matar a sede do sertanejo, ancorado no histórico de obras públicas inconclusas de abastecimento hídrico. Esses questionamentos são expostos e materializados na série de reportagens "A verdade sobre a transposição do rio São Francisco", admitindo posicionamento frente ao objeto em questão e por isso os conteúdos e as formas das notícias se assemelham à Propaganda.

\section{Conclusão}

A partir dos resultados do presente estudo é possível perceber que as posições contra e a favor da transposição do rio São Francisco sempre estiveram presentes desde o início do governo FHC (1999-2002) até o final do governo Lula (2003-2008) no jornal Estado de Minas. Os resultados traduzidos a partir do dendograma mostram que o jornal possui representações sociais sobre a transposição semelhantes e discrepantes nos dois tempos políticos citados. Contudo, elementos representacionais vão se agregando ao objeto social ao passar dos anos na medida em que determinados eventos ocorrem como, por exemplo, o uso das águas da transposição para fins econômicos no ano 2004, desencadeando todo um pensamento contrário ao projeto.

Ao que parece os estados que doam as águas são majoritariamente contra ao projeto em virtude dos impactos ambientais gerados ao rio São Francisco. Levando-se em consideração de que o rio, em vários pontos ao longo de sua extensão, encontra-se bastante degradado, a defesa da revitalização do curso de água e oposição mais contundente ao projeto se agrava e aparece nos estados da Bahia, Pernambuco e Minas Gerais, todos doadores das águas. Assim, é possível que essas posições de desaprovação e aprovação ao projeto estejam ligadas aos estados da federação, se estes são doadores ou receptores das águas, devendo estudos futuros investigar como outros estados doadores e receptores das águas também entendem o fenômeno da transposição e fundamentam suas posições em relação à problemática da crise hídrica.

Teoricamente isso tem relação estreita com o jornal e sua função a partir dos Sistemas de Comunicação (Moscovici, 2012). É possível perceber que a posição do noticiário 
em relação ao fenômeno que se leva em consideração determina os conteúdos e as formas das reportagens, orientando assim as representações sociais sobre esse fenômeno. No jornal Estado de Minas, por estar localizado em MG, estado onde encontra-se a nascente do rio São Francisco e corta parte do estado, e os outros estados também doadores das águas da transposição, as notícias buscam a revitalização e mostram o cotidiano do rio, a partir de relatos de pescadores, ribeirinhos, o que indica um tipo de notícia específica, diferente dos estados por onde o rio não passa.

Por fim, em virtude das constantes estiagens em regiões brasileiras nessa última década, medidas são discutidas e ponderadas para remediação da seca, como é o caso da transposição do rio Paraíba do Sul, no estado do Rio de Janeiro para o sistema Cantareira, no estado de São Paulo. O que se pode notar com o episódio até o momento é que a possibilidade dessa transposição novamente gerou grandes debates, contando com as resistências de políticos e técnicos do estado doador das águas, tal qual o projeto da transposição do rio São Francisco. Dessa forma, o presente estudo traz reflexões de como os discursos sobre uma grande obra hídrica se relacionam com os efeitos da seca no Nordeste brasileiro, devendo outros estudos investigarem como essa nova transposição se relaciona com a seca no sudeste brasileiro.

\section{Referências}

Agência Senado (2012). O que é o projeto de transposição do Rio São Francisco. Recuperado em 05 janeiro, 2016, de http://www12.senado.gov.br/noticias/materias/2008/02/14/o-que-e-o-projeto-detransposicao-do-rio-sao-francisco.

Allain, J. M., Nascimento-Schulze, C. M., \& Camargo, B. C. (2009). As representações sociais de transgênicos nos jornais brasileiros. Estudos de Psicologia, 14(1), 21-30.

Agencia Nacional de Águas (2014). Conjuntura dos recursos hídricos no Brasil - Encarte Especial sobre a Crise Hídrica. Recuperado em 05 janeiro, 2016, de http://conjuntura.ana.gov.br./docs/crisehidrica.pdf.

Camargo, B. V. (2005). Alceste: um programa informático de análise quantitativa de dados textuais. In A.S.P. Moreira, B. V. Camargo, J. C. Jesuino \& S. M. Nóbrega (Orgs.). Perspectivas teórico-metodológicas em representações sociais (pp. 511-539). João Pessoa: Editora Universitária UFPB.

Carvalho, L. A. \& Espíndula, D. H. P. (2014). Vozes da seca: representações da transposição do rio São Francisco. Arquivos Brasileiros de Psicologia, 66(1),135-151.

Castro, C.N. (2011). Transposição do rio São Francisco: análise de oportunidade do projeto. Rio de Janeiro: Instituto de Pesquisa Econômica e Aplicada.

Cemig (2012). Energia da gente: 50 anos de Três Marias. Recuperado em 05 janeiro, 2016, de https://www.cemig.com.br/sites/Imprensa/ptbr/publicacoes/Documents/Energia\%20da\%20Gente/EG91_final.pdf

Coutinho, M. P. L., Araújo, L. S., Coutinho, L. M., Morais, L. C. A., \& Batista, J. R. M. (2014). Eleições presidenciais no Brasil: o que veicula a mídia impressa. Psicologia e Saber Social, 3(2), 247-252.

Departamento Nacional de Obras Contra as Secas (2009). 100 Anos de DNOCS: marchas e contramarchas da convivência com as secas. Recuperado em 13 setembro, 2012, de http://www.sei.ba.gov.br.

Diários Associados (2016). Estado de Minas (MG). Recuperado em 22 novembro, 2016, de http://www.diariosassociados.com.br/home/veiculos.php?co_veiculo=29. 
Espíndula, D. H. P. (2010). Da ficção à realidade: estudos sobre formação e desenvolvimento das Representações Sociais da clonagem humana. Tese de Doutorado, Universidade Federal do Espírito Santo, Vitória, Brasil.

Espíndula, D. H. P., \& Trindade, Z. A. (2013). Clonagem humana: um estudo sobre a gênese das representações sociais. Psicologia e Saber Social, 2(2), 176-190.

Jodelet, D. (2001). Representações sociais: Um domínio em expansão. Rio de Janeiro: UERJ.

Leitão, J. A., \& Santos, M. S. T. (2012). Imagens jornalísticas e representações sociais: a imagem dos sertões. Intercom - RBCC, 35(1), 133-155.

Meiron, J. (2009). TransPosição Francisco. São Paulo: Annablume.

Moscovici, S. (2003). Representações sociais: investigações em psicologia social. Petrópolis: Vozes.

Moscovici, S. (2012). A psicanálise, sua imagem e seu público. Petrópolis: Vozes.

Nascimento, M. G. (1998). Migrações Nordestinas para a Amazônia. Revista de Educação, Cultura e Meio Ambiente, 2(12), 01-13.

Oliveira, F. C., Nascimento-Gianordoli, I. F., Santos, T. L. A., \& Freitas, J. C. (2015). Fronteiras e pertenças: representações sociais e dinâmicas identitárias do tráfico de drogas na revista Veja (1968-2010). Psicologia e Saber Social, 4(2), 277-297.

Ribeiro, M. B. (2010). Transposição - um projeto para reflexão. In M. M. R. Quintiere (Org.) Transposição do São Francisco: uma análise dos aspectos positivos e negativos do projeto que pretende transformar a Região Nordeste (pp. 35-62). Curitiba: Juruá Editora.

Souza, L. \& Menandro, P. R. M. (2007). Pesquisa documental em Psicologia: A máquina do tempo. Lógicas Metodológicas: Trajetos de Pesquisa em Psicologia. In M.M.P. Rodrigues \& P.R.M. Menandro (Orgs). Vitória: GM Gráfica Editora.

Vasconcellos, K. M. (2013). A representação social da família: desvendando conteúdos e explorando processos. Tese de Doutorado, Universidade de Brasília, Brasília, Brasil. 